Portland State University

PDXScholar

6-16-2021

\title{
Engaging Ecological Narratives: An Inquiry into Place-Based Knowledge and Disaster Risk Reduction in Gozo, Malta
}

Ella S. Richmond

Portland State University

Follow this and additional works at: https://pdxscholar.library.pdx.edu/honorstheses

Part of the Anthropology Commons, and the Other Social and Behavioral Sciences Commons Let us know how access to this document benefits you.

\section{Recommended Citation}

Richmond, Ella S., "Engaging Ecological Narratives: An Inquiry into Place-Based Knowledge and Disaster Risk Reduction in Gozo, Malta" (2021). University Honors Theses. Paper 1045.

https://doi.org/10.15760/honors.1071

This Thesis is brought to you for free and open access. It has been accepted for inclusion in University Honors Theses by an authorized administrator of PDXScholar. Please contact us if we can make this document more accessible: pdxscholar@pdx.edu. 
Engaging Ecological Narratives:

An Inquiry into Place-Based Knowledge and Disaster Risk Reduction in Gozo, Malta

by

Ella Richmond

An undergraduate honors thesis submitted in partial fulfillment of the requirements for the degree of

Bachelor of Arts

in

University Honors

and

Anthropology

Thesis Advisor

Jeremy Spoon, Ph.D.

Portland State University 


\section{Introduction}

In a globalized world where knowledge production takes place in a wide range of localities, it is difficult to be conscious of dominant narratives and how they impact our perceptions. Like many discourses, those of climate change, risk, and disaster, are primarily framed through a technocratic lens that values scientific knowledge over other ways of knowing and understanding the world (Mercer et al. 2010, 218). The act of controlling such narratives is an intentional arm of western-particularly U.S.-imperialism that functions both internally ${ }^{1}$ through propaganda and suppression as well as abroad through mechanisms such as military occupation and ideological hegemony (Forgie 2014, 57-73; Klein 2007; Dupuy 2011; Martin 2015; Pérouse de Montclos 2014). When local perspectives and knowledge are not included or accounted for in global climate and disaster discourse, and outside insight is prioritized, this negligence can result in harm; avoiding such insight can limit possibilities for risk reduction and disaster prevention. We tend to interpret risk and subsequent risk-response by utilizing generalized western-specific paradigmsthat are not necessarily the most effective in every community-rather than referring to localized knowledge. Then, when peril strikes, institutions and practitioners born of the same technocratic bodies of knowledge are dispatched with the task of 'rescuing' those very communities whose harm they engendered. This results in actors "nurturing long-term risk through short-term remedies" (Torry 1978, 302). If strategies to reduce vulnerability are created at the local level, community goals can begin to be prioritized rather than defaulting to reliance on these larger

\footnotetext{
1 The term "Internal Colonialism," utilized primarily in Black liberation discourses, refers to the colonial relationship between White and Black America where Black Americans experience domestic colonialism, despite their location within the metropole (Allen 2005, pg.2-3). Recently this term has been adopted by Latin American Scholars and activists to conceptually link the experience of those in the "third world" to the experience of "third world people" within the U.S. In other words, this re-conceptualization of the term serves to highlight the continuation of the colonial relationship despite the absence of a formal colonial administration (Allen 2005, pg.10).
} 
entities. In an effort to invigorate capacity for locally framed resilience in communities rather than be forced to adopt the 'support' of outside institutions, corporations, and predatory humanitarian governments, initiative must be taken to seriously assess risk and mitigate hazards prior to the onset of disasters. This task is accomplishable only through first recognizing the inherent value of knowledge rooted in communities and place (Mercer et al. 2010).

In order to explore the dissonance between global and localized knowledge, this effort will utilize a case-study of climate narratives and environmental perceptions in the Mediterranean country of Malta, specifically the island of Gozo. Gozo is one of three main islands in the Mediterranean Sea that makes up the Maltese archipelago. Gozitans have a unique relationship with the environment due to their primarily maritime livelihoods juxtaposed with relatively reduced water access and scarcity (Allen 2014). This relationship is confounded further by Gozitans' 7,000-year history of occupation, invasion, and uprising spanning from prehistoric arrival to modern day Maltese independence and incorporation into the Eurozone (Malta Tourism Authority 2021).

Malta has been continuously listed in the World Risk Index (WRI) as the second safest country in the world, despite recent controversy over the fallibility of this ranking in Maltese media (Leone Ganada 2018; Zammit 2018). Though the WRI utilizes a diversity of indicators, due to the scale of their approach and utilization of aggregate data, their rankings do not necessarily speak to the complexity of environmental interaction in a given community. Globally, the frequency of natural disasters our planet experiences in a given year has increased by over 10 times in the last several decades and is expected to increase substantially in coming years (ETR 2020, 5). Disasters are not isolated events but rather "long-unfolding processes" that become catastrophic when natural phenomena meet existing vulnerabilities (Barrios 2020, 23). Despite the overwhelming 
evidence suggesting that the majority of hazards are preventable with reduced vulnerability, far more resources are invested in disaster response rather than disaster prevention (Barrios 2020, 23 24). When disaster response is prioritized over disaster prevention, it reduces the temporal window available for responding in an effective as well as culturally and geographically specific way.

This multi-method ethnographic inquiry utilizes two phases of research to articulate how elements of Gozitan relationships to the environment are culturally and socio-politically unique and place based, differing from national and global climate narratives and impacting perceptions of risk and preventative action on the island. The first phase of research utilized archival and observational data to inform and buttress the second phase of research which employed informal and semi-structured interviewing. The results of ethnographic research inform this thesis, which serves as a case study in understanding culturally specific environmental relationships and placebased knowledge. Literature within the discourses of disaster studies, development, and political ecology provide additional evidence to substantiate the claims put forth in this paper (Robbins 2012; Koons 2020; Oliver-Smith 2020; Robbins and Moore 2013; Purdy 2016; Bergman 2019; Adger 1997; Klein 2007; Berkes 2008; Mercer et al. 2010; Berkes and Turner 2006). I argue that the acknowledgment of Gozitan localized knowledge regarding climate and hazards—as opposed to conventionally recognized, technocratic knowledge-has the potential to reduce community vulnerability to hazards that prefigure calamity. These findings indicate the necessity of a paradigm shift in the way disaster scenarios are conceptualized and prevented in regard to Gozo, and represents the potential of ethnographic research relating to place-based knowledge at large.

Within the literature on the topic of disaster and perceptions of risk in Gozo, there is information available in terms of seismic monitoring and scientific data on incremental climate changes on the island (Cilia 2019; Portelli 2010). This literature suggests that national responses 
and action towards hazard reduction in events such as tsunamis and other seismic disasters, is not commensurable to the critical threat that they pose (Cilia 2019). Accordingly, these scholars affirm that coastal vulnerability in Gozo is significant and warrants the attention and action of the public and relevant stakeholders, warning that without prioritizing risk reduction, the possibility of adverse consequences is ever-increasing (Portelli 2010, 106). Other studies suggest climate change concerns relating to the tourism industry, heritage sites, and conservation-many focusing on insights at the national level (Dodds and Kelman 2008; Satariano and Ritienne 2019; Mifsud and Sultana 2019; Jones 2017; Galdies 2016; Conrad et al. 2019). Alternatively, sparse literature exists that takes into account local perspectives, knowledge, and ways of relating to and interacting with the climate - a category of information that is rich, complex, and deserving of expansion (Galdies 2016; Heinze 2016, Allen, 2014). The results of the data collected in this project emphasize the complexity of local relationships to the environment, and the significance of understanding and accounting for the multifaceted factors at play in a given cultural context prior to the onset of potentially catastrophic events. Valuing and handling local knowledge with as much vigilance and urgency as we do scientific predictive models is of utmost importance if calamity is to be prevented in locales such as Gozo.

\section{Theoretical Framework and Key Terms}

Prior to discussing the way in which Gozitan relationships to the environment are culturally distinct and have tangible impacts on climate change narratives, perceptions of risk, and sociopolitical action, it is necessary to discuss human-environment relationships more broadly. This is fundamental to this research because how we perceive the world influences our interactions with it (Galdies and Galdies 2016; Johnson-Laird and Miller; ARGOS 2016). Considering possibly 
unfamiliar conceptual orientations to the environment can help us to understand topics relating to the climate and place-based knowledge in generative ways; this can assist us in breaking out of derivative perspectives that hinder potentially inventive solutions and approaches to issues (Mercer et al. 2010; Lejano et al. 2013; Cronon et al. 2004; Berkes 2008). Theories that give context to the significance and relevance of these human-environment relationships shape how I conduct and analyze this research. Therefore, I will be analyzing and discussing this research through the lenses of political ecology as well as the fallacy of the nature-culture dichotomy. Additionally, I will discuss the term 'resilience' as it relates to this research and will draw on discourses of 'Traditional Ecological Knowledge' (TEK) to help explain the function of place-based knowledge in this context.

\subsection{Theory: Political Ecology and the Fallacy of the Nature-Culture Dichotomy}

Political ecology posits that there is a crucial intersection between ecological phenomena and political, economic, social, and cultural forces. This is significant in that these political factors - being geographically and culturally distinct-indicate a plurality of possible climatic relationships, making it unreasonable to employ any single, uniform approach to topics of ecology and crisis. Robbins (2012, 3), a scholar of environmental studies, utilizes a political ecology approach to argue that ecological matters are innately political and that political matters are innately ecological. For example, a Gozitan consultant sharing that their sense of safety is increased by recent Maltese incorporation into the EU, and their subsequent action/inaction related to this imagined security, is undeniably ecological; similarly, if a climatic event occurred in Gozo, whether or not it were to cause harm, it would be intimately tied to the political context of that given moment. In this research and in the case of Gozo, there is an opportunity to analyze the political context prior to any ecological catastrophe; informing preventative action that is 
culturally specific rather than disaster response that relies on generalized understandings of ecological relationships. Koons (2020, 95-98), a disaster management practitioner, acknowledges that in rapid disaster response, there will always be gaps in applying "generalizable principles and standards" of action as disasters are "locally specific and unique." An example of this can be seen in Oliver-Smith's (2020, 205-211) case studies mapping post-disaster initiatives, where the resettlement of communities takes place as a method of response. These case studies speak to the fallibility that can exist in broad approaches to disaster recovery and the myriad of cascading effects, such as enduring trauma due to displacement, that 'solutions' like resettlement can have. With the privilege of time, it is possible and ideal to critically understand Gozitan-environment relationships and perceptions of risk through the lens of political ecology and therefore take the preventative measures necessary to mitigate potential hazards with less need for external support.

Humans and nonhumans are not separate, nor do they function in separate spheres of interaction (Purdy 2015, 2016; Robbins 2012). This notion exists in opposition to the idea of the 'nature-culture dichotomy' (or divide) which is the theorized distinction and tension between these two components. Though, in the words of Purdy (2016), "nature no longer exists independent of human activity" and remains alive only in the conceptualization of "nature" that we have articulated and the meaning we have ascribed to it. Therefore, in the Anthropocene, the epoch referring to human impact on the world, we are unable to engage the nonhuman world without also engaging the human (Purdy 2015, 2016; Robbins and Moore 2013). Humanity is typically portrayed as adjacent to the natural world or - especially in the context of the climate crisis - in opposition to it. Anthropocene scientific discourses (including environmentalism, restoration ecology, etc.) are often predicated on the notion of humanity as a destructive force that has transformed the earth to a point of irreversibility, an approach that while rooted in some rightful 
sense of tragedy, seeks to return to a sort of 'naturalized' state, essentializing or making static in time the idea of a lost past (Robbins and Moore 2013, 8-9). Rather, in addition to being an unsubstantiated approach to general climate health as no clear boundaries can be drawn to separate humanity from the nonhuman, recent scholarship suggests that "if there ever was a 'rightful' natural condition to which to return, it is inaccessible to us in a world of global environmental change" - noting the unproductive nature of theorizing any sort of climatic future where human and nonhuman life are rigidly apportioned (Robbins and Moore 2013, 5). What we deem to be the natural world is neither an isolated nor separate entity from us as humans but a co-creation of our collective actions and interactions (Purdy 2015, 2016, Robbins and Moore 2013). Robbins goes to such lengths as to suggest that the very act of recognizing what we deem to be 'nature' as "explicitly political", or a human-nonhuman collective process, would allow active strides in revolutionizing our response to environmental crisis (Robbins 2012, 4). This discourse helps us to develop a praxis rooted not in the false dichotomy between 'us' and 'nature', but in the understanding that we are simply a constituent part of the complex process we identify as the 'environment'. This perspective is relevant to this research in that it allows us to consider the larger sphere of interaction relating to environmental relationships and perceptions of risk in Gozo.

Political ecology and the fallacy of the nature-culture dichotomy - while distinct-are deeply complimentary. Political ecology is made increasingly applicable by the notion that the 'human' is inseparable from the so-called 'environment' which is crucial in understanding how it is inherently political. A prominent aspect of these frameworks, especially in disaster and development discourses, is the acknowledgement of the vulnerabilities and social conditions that precede catastrophic events, allowing them to rapidly evolve from mere hazards (Oliver-Smith $2009,13)$. In other words, it is often not a storm that is disastrous in and of itself, but a storm in 
combination with precarious housing situations, unstable resources, and other human-made circumstances that compound the impacts of a climatic event and cause harm. As such, in anticipation of or in response to an ecological crisis or phenomena, we cannot divorce our understanding of an event from its political context.

Ways of relating to and being a part of the environment differ globally and culturally. As I find in my ethnographic research in Gozo, socio-political relationships with the non-human world have a consequential impact on perceptions of risk and subsequently on disaster preparedness. In this way, the generic risk assessment models and preventative action plans of technocratic knowledge production are less likely to be effective, because they apply a generalized solution to issues that are very place-based and contextual. As such, this type of approach reinforces a classic gap that exists between theory and practice (Oliver-Smith 2020, 198-214).

\subsection{Key Terms: Resilience and Traditional Ecological Knowledge}

The term 'resilience' is useful to define and complementary to the aforementioned theoretical frameworks. Resilience, according to Portelli (2010, 26), a scholar of sustainable environmental resource management in Gozo, is "the amount of change the system can undergo and still remain within the same domain of attraction; it is also the degree to which the system is capable of self-organization and finally resilience is the degree to which the system can build the capacity to learn and adapt." The term can also be defined by the ability of a community or population to absorb change and disturbance and return to an equilibrium state (Adger 1997, pg. 5-6). Resilience is arguably among the most contested terms in discourses relating to disaster and recovery, as it is frequently seen as something to strive for in post-disaster contexts but is quite subjective. Disaster and resource management scholar Bergman (2019) calls into question resilience as a desirable goal because it insists on the returning to existing conditions; conditions 
which may have been far from ideal and even perpetuated the vulnerabilities that welcomed calamity. Centering local perspectives and knowledge in the pre-disaster milieu can help support communities in achieving a level of resilience that serves their needs and livelihoods if ever a disaster occurs, rather than succumbing to the idealized development agendas of larger 'philanthropic' entities (Klein 2007).

The term 'Traditional Ecological Knowledge' (TEK) refers to the wealth of information and expertise that informs Indigenous ways of knowing and being. TEK encompasses the "social attitudes, beliefs, principles, and conventions of behavior and practice" which are derived from individual and collective histories (Berkes 2008, 5). While scientific knowledge generally functions at the global level, Indigenous knowledge is localized and acquired by people over time through experiences, relationships, and practices (Mercer et al. 2010, 217). Despite Gozitans having a differing history and relationship to the non-human world than Indigenous people whom this term primarily serves, TEK can function as a tool for understanding how Gozitan linguistic predispositions, lore, and socio-political contexts are useful, and can provide insight into disaster circumstances that technocratic knowledge cannot. A significant aspect of TEK is its inherent adaptivity as it is bound to social and cultural life, which is constantly undergoing change. This adaptivity is recognized and accounted for in two distinct models: the ecological understanding model and the crisis depletion model (Berkes and Turner 2006). The ecological understanding model describes incremental collective learning, whereas the crisis depletion model denotes the new practices and knowledge that can emerge from approaching new situations in a disaster scenario (Berkes and Turner 2006). These aspects of TEK take into account shifting social and ecological systems that western science models often neglect. In a research study in Cat Hai, Vietnam that aimed to better understand the role of TEK in disaster risk management, results 
showed that despite the valuing of modern technology over TEK, TEK served as a major predictive and prevention measure in the community (Thi Bich Hop et al. 2017, 27). The community developed TEK through "detailed observation of the environment including the behavior of animals, changes in morphology and physiology of plants, cloud patterns, and the appearance of the moon and other celestial bodies" (Thi Bich Hop et al. 2017, 26). Individuals in the community explained that belief in these practices were embedded in their livelihoods as their ancestors had used these prediction strategies and knowledge for centuries (Thi Bich Hop et al. 2017, 27). Though this article is specific to a particular community, it speaks to the relevance of place-based knowledge and perspectives on disaster prevention and mitigation - an approach that is useful when interacting with the Gozitan climate narratives presented in this paper.

\section{Context}

Gozo, Malta is situated in the Mediterranean Sea within the Maltese Archipelago. Malta gained its independence as a republic in 1974 and became part of the European Union in 2004. Gozo is largely economically dependent upon its tourism industry and its few natural resources such as farming, fishing, and beekeeping, as well as wine, lace, limestone and salt production. Gozo has a deep history of immigration and colonization beginning in 5000 BC when Sicilian farmers settled there. Gozo's desirability as a tourism destination is due in part to the presence of historically and geologically significant sites, including some of the oldest structures in the world, such as Homer's famous Calypso's Cave and the recently collapsed Azure Window. Gozo’s deep history and culture has produced a rich oral and written record of mythology and folklore, much of which connects to the natural environment and the sea (Attard 2010; Cassar-Pullicinco 1992). 


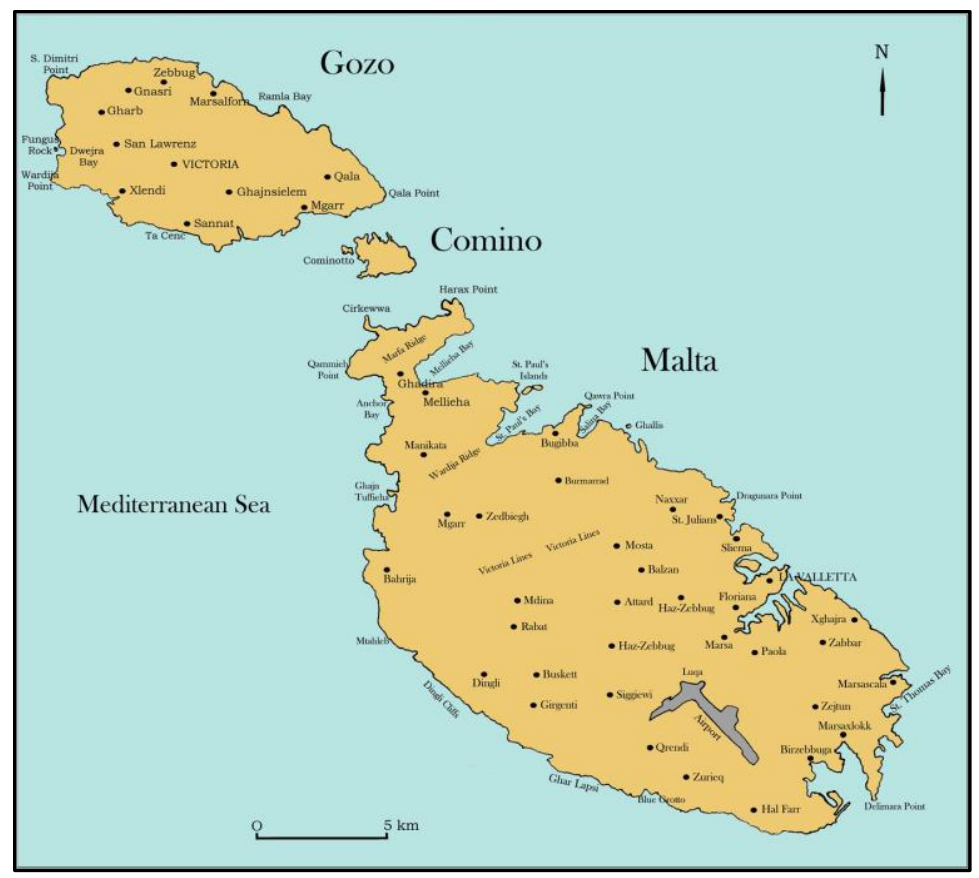

Fig. 1. Map of Malta, Gozo, and Comino, including study areas. Map by Salvatore Brullo et al.

Malta has been listed as the second safest country in the world according to the World Risk Index (WRI) as early as 2012 and has maintained that title since. This is significant as Gozo is a small island that is relatively resource dependent with aging infrastructure that would seemingly be vulnerable to climate disasters. Given that small islands are historically vulnerable to environmental calamity, Gozo is unique in its supposed lack of notable climatic events and highranking place on the WRI for several consecutive years. In a 2010 case study assessing vulnerability to coastal hazards in Gozo, Portelli (2010, 45-48) notes five distinct types of natural events that have taken place in Gozo that were identified as coastal hazards, including tsunamis, storm surges, coastal flooding, sea level rise, and landslides. Though these events are part of Gozo's history, many occurred prior to the living memories of those inhabiting Gozo today. Others 
such as sea level rise can be considered a "latent hazard" as they are incremental and not always noted in public discourse as the source of negative impacts (Portelli 2010, 47). In this study, Portelli (2010, 19-24) also identifies some of the key vulnerabilities of the island, including its topography, overpopulation, and the intensive development of coastal areas. Another study shows that while tourism has been impacted by climate change, 'Malta's Sustainable Tourism Policies' have failed to address it outside of heritage sights or for the sake of marketing (Dodds and Kelman 2008, 64). In Malta, and especially Gozo, increasing pressure falls on the tourism sector to simultaneously maintain economic success and avoid further environmental degradation.

Environmental politics in Malta are evident at the local, national, and EU level. Examples of this include (but are not limited to) collective action through the Catholic church, labor unions, radical community organizing (Moviment Graffitti and Żminijietna Voice of the Left), ENGO's (environmental non-governmental organizations), and the Green Party (Alternattiva Demokratika) (Briguglio 2015, 7-15). Since Malta's EU accession, some environmentalist groups have found increased success lobbying at the EU rather than the national level and have implemented some environmental legislation relating to pollution, ecological information access, and conservation (Briguglio 2015, 9). However, despite recent changes in land management and the sustainability discourse, public concern has increased relating to the country's ability to adapt as the effects of climate change continue to advance. Several sources outside the academy, such as local newspapers and blogs, voice desire for increased preventative measures and disaster risk reduction. In a 2018 interview with the Times of Malta, climatologist James Ciarlo warns of potential harms, such as coastal flooding, water scarcity, extreme weather events, and industry affecting marine biodiversity changes, increases in invasive species, and temperature changes affecting fisheries and aquaculture, arguing, "we're talking of shifts that we're not necessarily equipped for: our 
infrastructure is set up for a climate we're used to" (Ganado 2018). In a 2019 survey, Malta Independent published that $92 \%$ of Maltese people see climate change as a serious threat (Malta Independent 2019). In another piece Dr. Geoff Main (in Zammit 2018) critiques the WRI itself and its calculation of risk, suggesting that Malta's ranking is preoccupied with land mass, its evergrowing tourist population, and historical records that are largely incomplete. Additionally, articles espousing the safety of Malta given its WRI rating have been met with much contestation by locals, who argue that much of the archipelago is high risk and very little preventative action has been taken.

Much of the available academic literature and public discourse relating to Maltese climate narratives and risk refer to Malta at the national level and rarely discuss Gozo explicitly. This is significant because Gozo is implicated in the legislation and governance relating to environment management, sustainability measures, and disaster risk reduction of Malta. However, I am not claiming that Maltese discourses on these topics express sentiments shared by all Maltese, or even all Gozitans, but hope to instead illustrate the complexity of this issue and frame where my research is located within this larger conversation. With this being said, perceptions of risk of and relating to Gozo are manifold and worth interrogating further.

\section{Methods}

My research therefore seeks to illuminate where Gozo fits into the national climate narrative and highlight Gozitan perspectives on this topic in order to inform locally applicable disaster risk reduction. My research questions include: 1) How do Gozitans situate themselves in relation to the environment; 2) How do Gozitan relationships to the environment shape perceptions 
of risk and socio-political action; and 3) How do Gozitan goals for hazard and disaster risk reduction differ from those at the national and global level?

\subsection{Positionality}

As an undergraduate student of anthropology, interested in a substantial topic on an island I only briefly encountered, my ethnography, like all ethnographies, will be incomplete, biased, and a reflection of my perspective on the world and my relationship to this topic. Anthropology, and all of its disciplines, provide ways in which we can see the world in new and interesting ways (Okely 2012). Through an anthropological lens, the world around one can be reshaped; by critically observing the world through such a lens, the individual can also be reshaped. This is the push and pull of anthropology and why bias is inherent in the work (Okely 2012). It is important to be reflexive about what preconceived notions I bring to this research, just as it is crucial that consumers of academic material understand the inability of any such research containing outside perspectives on a situation to be purely objective. The objective-subjective binary is deeply rooted in our conceptions of science and language and is a dichotomy that serves technocratic knowledge systems, giving it power to discern 'what is worth knowing,' a question that is not answerable by any one institution (Aikenhead 2008, 584).

I acknowledge that as a female-coded, neurodivergent person of white settler-colonial descent, I am both afforded distinct privileges through the way I am perceived and able to navigate the world, as well as confronted by unique challenges specific to my own experience. Politically, I am an abolitionist and therefore tend to be skeptical of corporate and institutional agendas, often approaching them critically or oppositionally, as I have witnessed and experienced direct harm by these forces and believe that many systems that perpetuate violence are not corrupted but functioning precisely how they were intended to. Though I am not in a position of wealth, there 
are certain financial hardships I have never known and there are undoubtedly class privileges I experience that I am actively working to be more conscious of. Each given aspect of my identity holds a certain amount of power and can provide access to and exclusion from spaces as well as directly and indirectly influence those that I inhabit. My positionality in conducting research is important in allowing readers to better contextualize my work. However, acknowledging my biases does not prevent any power differentials they may cause nor does it ensure that they will arise, just as naming certain aspects of my positionality does not make my lived experience reducible to those qualities (Robertson 2002, 789). Given the colonial history of anthropological practice this sort of reflexivity is useful but should not be construed as the setting up of a false asymmetry between researchers and consultants (suggesting that each are defined respectively by the theorized 'colonial encounter'), who are fully capable of collaboration and mutual exchange (Robertson 2002).

I believe it is important to note the intent behind research, in this case what led me to pursue this topic. My adolescent years were in-part shaped by existing in settings of volunteerism and aid distribution which allowed me to experience first-hand the ego-assuaging practices of disaster response by the same structures and institutions that have created contexts of harm. I came to learn that modern humanitarianism and disaster response can function as another faction of imperialism that perpetuates and profits off of the same violence it claims to alleviate, oppressing and harming its supposed beneficiaries. The 'Humanitarian Industrial Complex' finds itself deeply embedded in the national and global consciousness and is not something that I can begin to extract within the scope of this paper (Dadusc and Mudu 2020; Klein 2007). However, working towards understanding the conditions that prefigure catastrophe as well as the narratives and perspectives that make up local relationships to the environment and perceptions of risk, informs the process of 
fostering agency and resilience locally over the long-term rather than invoking dependency and outside involvement in situations of urgency and crisis.

Historically, anthropologists and professionals in a variety of fields abused the power granted by the lens of academia and caused undue harm in the name of research (Alcadipani and Hodgson 2009; 128, 131-132). I have taken steps to avoid such harms by participating in IRB certification and ethics training as well as practicing informed consent. My research was compiled through the gracious information sharing of consenting adult individuals whom I greatly respect and have gained immeasurable insight from. This is the position from which I am speaking.

\subsection{Research Design}

In this research, I utilized a mixed method ethnographic approach to examine the implications of Gozitan-environment relationships on perceptions of risk and preventive action from a variety of angles. Utilizing multiple research methods in conducting ethnographic research contributes to ensuring validity in results and reduced researcher bias (Hawkes and Rowe 2008, 631-632).

I conducted this research in July of 2019 in Gozo, Malta with guidance and support from Portland State University faculty and advisors of the Off The Beaten Track Applied Anthropology Field School. Throughout the course of this research, I utilized an initial phase of archival research, and observation as well as a second phase of informal and semi-structured interviewing. A primary bias that exists in my data collection across each of my methods that must be addressed, is the near absence of women and non-gender conforming consultants. My intention was not to highlight the perspectives of specifically male consultants; however, I found that Gozitan women tend to spend more time in private (as opposed to public) spaces and therefore were more inaccessible to engage. Additionally, when I did interact with women it was typically while they were with children or at 
their place of work, rarely in places of leisure such as cafes, bars, or bays. This research is also limited both by my positionality as a non-Gozitan person and my inability to collect a larger sample of interviews due to the scale and timeline of the project. Given the temporal restrictions of my research project, the scope of claims that can be made from my results are limited.

To contextualize my choice of methods for this research, I entered the field with preliminary research on Gozo through academic literature as well as through the online publications 'Times of Malta,' and 'Malta Independent,' which provided much insight into Maltese sentiments towards climate, risk, and safety, which became the basis of my initial interview questions. The comments left below these articles in both Maltese and English illustrated a range of opinions and critiques regarding the national government, the EU, and whether enough was being done to prepare for and mitigate the impacts of climatic events. Though this information was rich and equipped me with a substantial basis of the types of issues that were at the forefront of Gozitan interest that went on to inform my data collection, it remained a flawed ethnographic method, as there is no distinct way of ensuring whether all commenters were indeed Maltese. Additionally, there is much division between local Gozitan perspectives and those of mainland Maltese and for the purpose of this project I focused on Gozitan perspectives specifically. Lastly, it was infeasible to gain informed consent to refer to or analyze this unpublished, though public, data.

\subsection{Data Collection and Analysis}

There are two primary components of my data collection: phase 1) informal observation and archival research; and phase 2) informal and semi-structured interviewing. Phase 1 of the data collection process served to inform, supplement, and corroborate Phase 2 of my data collection, which was systematic and regimented. 


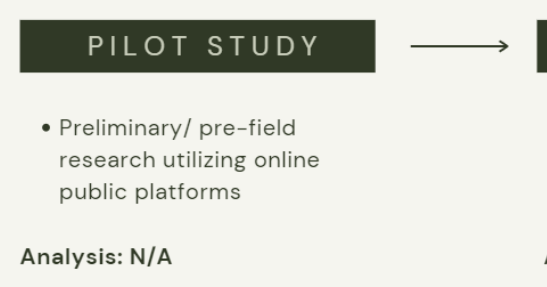

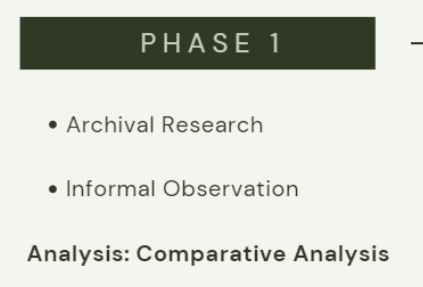

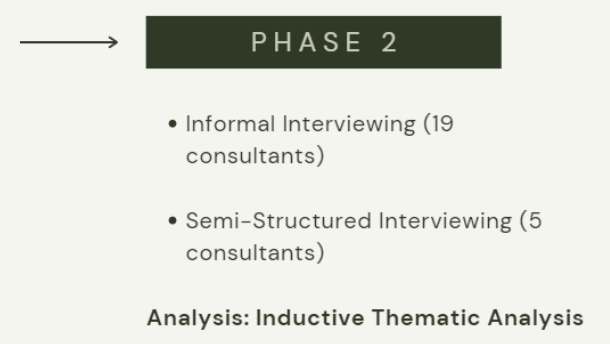

Fig. 2. Visualization of Research Design

\subsubsection{Phase 1: Contextualization}

\section{Archival Research}

Archival research took place throughout the data collection process at The Archives of Gozo, with the unit of analysis being mentions of relevant thematic elements. In order to inform and confirm questions and emerging themes, I scoured linguistic, folkloric, historic, and environmental archives. This method served to provide additional context to the informal and semi-structured interviews conducted. Additionally, I conducted a literature review utilizing online databases in an effort to better understand where Gozo fits into climate and disaster narratives at the national and global level. I also searched for studies and literature pertaining to local perspectives and knowledge.

These data contributed to my understanding and analysis of the observational and interview data. Both archival and online databases served to substantiate or problematize themes brought up by consultants through a comparative analysis, where relevant thematic elements were understood in relation to observational and consultant interview data.

\section{Informal observation}


Informal observation was ongoing throughout the research process and served as a comparative tool, as well as a way to process and tangibly situate what was being articulated through interviews in the real world; the unit of analysis consisted of observations which directly affirmed or complicated consultant perspectives. This method did not include engagement with people or conversation but simply involved the acknowledgement of infrastructure, events, and occurrences that provided insight into emerging questions and themes. This included walking through Xlendi Bay during an evening storm as well as walking through the next morning and observing the visible effect that the storm had on individuals, infrastructure, and livelihoods. It also included noting signage, symbols, or landmarks that were indicative of risk prevention or safety, as well as aspects of the physical world that either validated or contradicted interview data.

These data served to buttress the themes revealed in my archival research and interview data. For this method, I conducted a comparative analysis, interrogating the similarities and differences evident between these observational data and that provided by consultants in phase 2 where informal and semi-structured interviews were conducted.

\subsubsection{Phase 2: Interviewing}

\section{Informal Interviews}

Upon arriving in Gozo, my ethnographic data collection began with informal interviewing, the unit of analysis being the individual. During this phase of the research, I approached 20 individuals, 14 of which had interest in participating in an informal interview. Additionally, one interview evolved into a group discussion with five consenting participants. The consultants in my informal interviews were Gozitan and all except for one considered Gozo to be their primary home (this individual was raised in Gozo and now spends summers there and other seasons elsewhere). Consultants ranged between the ages of 26 and 79. Only two of the consultants identified as female 
with the remaining 17 consultants identifying as male. It was important to begin with this method as it allowed me to efficiently gather a wide range of responses and reactions to questions regarding climate, risk, and safety. I chose two distinct site types for this initial phase of research collection: 1) public centers of Gozitan life such as the bus/bus stop, pastizzeria, local outdoor dining, and other prominent spots within the city center; and 2) waterfront locations and known historic areas such as the site of the Azure Window, the Megalithic Temples of Malta, and bay-side touristic shops or eateries. The intent of conducting informal interviews at these different locations was to gauge how proximity to the sea and sea-based livelihoods impacted perceptions of climate-related risk. This research method was intended to gain an initial understanding of how terms such as 'emergency,' 'climate change,' 'risk,' 'safety,' and 'disaster' are perceived in Gozo and what types of themes conversations around these words evoked.

I transcribed these interviews for analysis. Interviews were thematically analyzed by indicating the frequency of key words and phrases as well as indicating sentiments that directly affirmed or negated the perspective of another consultant. I utilized an inductive thematic approach in which the data is not confined by pre-existing expectations nor dictated by a given conceptual structure (Bernard 2017, 7). Rather, the data itself guided the structure of my analysis, characterizing the themes that emerged.

\section{Semi Structured Interviews}

Following the informal interviewing phase, I conducted semi-structured interviews with five consultants, once again, the unit of analysis being the individual. The first interview took place with an 85-year-old male Gozitan Salt Pan worker in Marsalforn who I encountered within my first week in Gozo. My second interview took place with a Gozitan man who I believe to be in his 50's-60's who I was introduced to as an excellent resource to those who have questions about the 
island. My third interview took place with a 35-year-old Gozitan woman who lives and works at the site of the Azure Window. My fourth interview was with a 24-year-old Danish woman who volunteers at the Emergency Response and Rescue Corps (ERRC) headquarters in Gozo. My fifth interview took place with a 27-year-old Gozitan student who goes to school in Malta and lives in Gozo. Each of the consultants were consenting adults who were willing to meet for about an hour to an hour and a half and have a conversation regarding a series of open-ended questions that I formed in response to the data that had been collected from the informal interviews. However, aware that the themes uncovered in the initial interviews were fairly surface level and that there was much I had yet to learn on the topic of climate and risk perception, I encouraged consultants to share whatever they felt significant about the topic and to only use my questions as guides.

I transcribed each of these interviews, and thematically organized them based on the themes that emerged in the informal interview data. At this stage, the analysis process became both inductive and deductive as the process remained inclusive of potentially new insights but was guided by the themes illuminated in the informal interview stage (Bernard 2017, 7).

\section{Results}

The results of this research reveal that Gozitans hold a variety of sentiments and perceptions towards risk and disaster that are in contradiction to statements of national safety and reduced hazards; these perceptions were notably impacted by language, lore, infrastructure, and political disposition. By and large, the average person "perceive(s) risk in a more complex, multidimensional way than do risk assessors," and available information on how one may respond to a crisis rather than simply perceive it is incomplete (Hawkes and Rowe 2008, 617). The results 
presented here indicate that Gozitans relate to the non-human world, and therefore perceive it, in ways that are not accounted for in scientific hazard and disaster mitigation discourses.

The pilot study I conducted — utilizing online publications such as the Times of Malta and Malta Independent as well as their respective public comments in order to provide insight into the nature of Maltese sentiments towards climate risk safety-provided a variety of insights. I found that though the national narrative aligned with the WRI rating of safety and low risk on the island, many perceivably Maltese commenters expressed several concerns related to infrastructural preparedness, coastal erosion and flooding, as well as lack of preemptive hazard mitigation. Others directly disagreed with the WRI and national narrative, arguing that climate change and recent environmental shifts pose a major risk to the island that they are unprepared to face and voiced support for increased research and attention to environmental hazards on the island. These sentiments were helpful in framing and affirming the presence of a significant conflicting narrative.

\subsection{Phase 1 Results}

Archival and database research conducted revealed that though much information exists in relation to conservation and environmental concerns relating to tourism, very little research has been published regarding hazard risk on the island. Only one research study related to environmental risk in Gozo was accessible. The archival, as opposed to the online, literature was difficult to analyze in that the relevant archives I came across were sparse and for many topics such as 'climate change' or 'the environment,' there was very little available information. The limited Gozitan literature I was able to find related to the climate was a book on weather and weather patterns. However, I found that the folklore and mythology archives were incredibly rich 
and detailed many of the environmental-based stories that had only been alluded to in my interviews.

Analysis of my observational research divulged a few notable contradictions between the built environment and Gozitan discussion of the built environment. How one perceives their environment cannot be 'inaccurate' as it is their own subjective experience. However, it is significant that as the outsider in this scenario, there were inconsistencies which indicated that I as the researcher perceived the environment differently than my consultants. Additionally, the observational research conducted showed that there are indeed a variety of features of the island that in combination with extreme weather or natural conditions could prove hazardous. I observed severe erosion and occasional loss of historic sites (ie. The Azure Window). I also observed heavy storms and strong winds that resulted in damaged storefronts, telephone lines, and water vessels. Additionally, "blackspots" or signage indicating a space where someone was killed or injured were observable along some streets and near some waterfronts. Construction projects and sites were visible across Gozo, particularly at Xlendi bay, Marsalforn, and Victoria. 'Luzzu', Maltese fishing boats, commonly sport an eye decal at its bow that was referred to by consultants as "the oculus", "the eye of osiris", or "the evil eye".

\subsection{Phase 2 Results}

In analyzing the conversations transcribed following my informal interviews, four key themes were identified utilizing a thematic analysis: 1) distinct language associated with disaster; 2) aetiology (the study of causation), oral histories, and lore as impacting risk perception; 3) tension between modernity and tradition; and 4) competing climate narratives.

Analysis of the conversations transcribed following my semi-structured interviews illuminated several sub-themes. I found that these interviews provided much deeper insight and 
context to many of the themes that surfaced in initial interviews. Each of the sub-themes included in this analysis were referenced by at least two consultants in the semi-structured interview phase and were often affirmed by more than two consultants. Within theme 1 , the following sub-themes were present: 1.1 linguistic differences between Maltese and English; 1.2 personification of climate and sea through pronoun usage; and 1.3 human vs. climate induced risk. Within theme 2 , the following sub-themes were present: 2.1 The Sunken Village; 2.2 Tromba and Dragunara; and 2.3 Protective eyes. Within theme 3, the following sub-themes were present: 3.1 controversy around construction; 3.2 place naming and place attachment; and 3.3 uncertainty related to change. Within theme 4 , the following sub-themes were present: 4.1 national/global vs. local narratives; 4.2 security in EU incorporation; and 4.3 risk management and the Emergency Response and Rescue Corps (ERRC).

\begin{tabular}{|l|l|}
\hline Data Collection Method & Themes \\
\hline Informal Interviewing & 1. Language Shaping Climate Discourse \\
\hline Semi Structured Interviewing & 1.1 Linguistic Differences Between Maltese and English \\
\hline Semi Structured Interviewing & 1.2 Personfication of Climate/ Prounoun Usage \\
\hline Semi Structured Interviewing & 1.3 Human vs. climate induced risk \\
\hline Informal Interviewing & 2. Place-Based Histories / Lore as Impacting Risk Perception \\
\hline Semi Structured Interviewing & 2.1 The Sunken Village \\
\hline Semi Structured Interviewing & 2.2 Tromba and Dragunara \\
\hline Semi Structured Interviewing & 2.3 Protective Eyes \\
\hline Informal Interviewing & 3.Tension Between Tradition and Modernity in Risk Reduction \\
\hline Semi Structured Interviewing & 3.1 Controversy around Construction \\
\hline Semi Structured Interviewing & 3.2 Place Naming and Place Attachment \\
\hline Semi Structured Interviewing & 3.3 Uncertainty Related to Change \\
\hline Informal Interviewing & 4. Conflicting Climate Narratives Impact Preventative Action \\
\hline Semi Structured Interviewing & 4.1 National/Global vs. Local Narratives \\
\hline Semi Structured Interviewing & 4.2 Security in EU Incorporation \\
\hline Semi Structured Interviewing & 4.3 Risk Management and the ERRC \\
\hline
\end{tabular}

Fig. 3. Data Collection Methods and Themes. 


\section{Discussion}

\subsection{Language of Climate, Language of Crisis}

Scholars argue that linguistic disposition can impact perception, a concept that has major implications on the study of crisis (Johnson-Laird and Miller 2013). Upon arriving in Gozo, it immediately became clear that I was not using the correct language to discuss environmental calamity on the island. I found right away that when terms such as 'emergency', 'disaster', or 'risk' were used in relation to the environment, conversation would be directed towards traffic incidents, construction accidents, or crime. In each interview, concern relating to natural or environmental hazards was never the first form of calamity to be mentioned. One consultant stated: "What you call disasters, here, don't kill people - they are inconveniences, yes, not really disasters." They then went on to describe the human role in disasters, and again drew a comparison between the U.S. and Malta, stating that we place blame on the conditions of the weather rather than on the condition's humans create that cause harm. Another consultant when provoked regarding this sentiment responded in reference to the sea, "she does not live to please us." This theme of personifying and prescribing pronouns (most often she/her) to the weather and particularly the sea was consistent as well as the endowing of agency to 'her.' A linguistic study revealed that the assigning of feminine or masculine articles to subjects in German and Spanish language impacted the way individuals discussed and described them (ARGOS 2016). This reinforces the role that language and particularly the personification of subjects can have on perception and speaks to the issue of ensuring the accessibility of climate and disaster discourses cross-culturally. However, as the aforementioned quote highlights, despite the intentionality that Gozitans afford the climate in these dialogues as a sort of living entity, they still do not pin the climate with responsibility for the 
calamity that human hazards create. Another consultant affirmed this by sharing that: "Human actions are what I consider disastrous." This is significant in revealing how some Gozitan perspectives relate to disaster and speaks to why the consultants referred to 'natural' or 'environmental' events far less than human caused harm in relation to disaster. This way of relating to the non-human world invokes the discussion of the fallacy of the nature-culture dichotomy, which exists counter to the dominant narrative of nature as distinctly separate from humanity, seen as operating chaotically and unpredictably (Purdy 2016; Purdy 2015, 2-3). In development and disaster discourses, the way that 'nature' is defined and interpreted, 'becomes embedded in management and administration regimes of state agencies, non-governmental organizations, and development projects" (Scoones 1999, 489). Therefore, Gozitan perspectives on humannonhuman interaction are not typically represented in the technocratic climate discourses, policies, and institutions that are in place to serve them if ever a disaster scenario occurs.

Both phases of research showed that there are several suffixes that exist in Gozitan language used to describe the temperament of the weather ( 7 suffixes indicated in interviews) and the sea (4 suffixes indicated in interviews). In most interviews this linguistic function served alongside personification of the sea and climate to indicate temperaments or 'moods' associated with what would generally be considered 'good' or 'bad' weather. When climate change was mentioned, consultants did not discuss it as something that poses a direct risk or is urgent but referenced it to indicate the inherent fluctuations of the weather and sea. An example of this, in reference to the impacts of climate change and increasing storms on salt production, one consultant shared:

There's always the storm. Sometimes she's good to us, sometimes we test her. There are good seasons, bad seasons, sometimes a break. The sun and the salt work together you know? — and sometimes the sea cooperates. 
A fisherman when posed with the question of how climate changes and extreme weather impact fishing, shared:

The weather is... well, can be bad I guess... for anyone really, but for me, yes. There are songs about her even... about the sea I mean.

These two quotes hint at a belief that seems to be twofold: 1) that the climate and sea have agency and function as beings; and 2) that fluctuations in the temperament of these being(s) is tied to human action and interaction. These consultant excerpts reinforce a recent case study that suggests that "hazard risk management on the island of Gozo is of crucial importance" yet, public awareness and preparedness related to coastal hazards has been minimal (Portelli 2010, 101; 103 104). Given the deep relationship to the environment that Gozitan consultants expressed, it is unlikely that they are simply oblivious to the hazards that exist. It is more likely that the language and approaches being utilized to enact widespread community awareness have not yet been accessible or compatible with Gozitan perspectives. Clearly, these excerpts speak to local awareness of climate and sea fluctuations or 'temperaments,' though Gozitans remain largely excluded from the larger climate change and risk reduction discourses. In failing to speak to local Gozitan perspectives, external practitioners and institutions have yet to succeed in creating the desired sense of urgency. Given the 'slow-onset' nature of climate change, instilling a sense of urgency in communities and the general public has been a widespread issue as its graduality "in effect, regularizes expectations of more frequent catastrophes" allowing 'slow-onset disasters' to continue to be defined as 'non-disasters' (Fiske and Marino 2020, 141-143). Further, despite the local environmental knowledge that coastal communities often hold relating to the frequency and intensity of climatic events (such as hurricanes, storm surges, flooding, and erosion), there is a notable trend of perceiving such events as "normal" as they have been "seen before, planned for, and seen earlier generations survive them" (Fiske and Marino 2020, 147). In this way, there is no 
lack of community and institutional knowledge, yet a gap exists between risk perception and the implementation of climate adaptation policies and action for slow-onset environmental shifts-inpart attributable to the lack of conversation and collaboration between place-based and technocratic knowledge systems.

\subsection{Climate as Being}

In recent years, climate scholars have proposed the role of narrative in environmental studies and the idea that "there are no clear distinctions between science and culture, society and nature, fact and narrative" (Lejano 2013, 2). Various folkloric and religious stories and histories yielded from interviews with consultants substantiated the notion that such lore is a prominent way in which people describe, discuss, and account for climatic events in Gozo. Accordingly, much of the built and physical environment in Gozo-including churches, homes, fields, valleys, cliffs, caves, wells, shops, and even entire towns—are imbued with lore (Attard, 42-45). Consultants shared several oral histories which serve to illustrate the complexity of Gozitan climate relations and narratives. However, the narrative lore coded within the conducted interviews are not comprehensive, and the beliefs shared do not represent the perspectives or experiences of all Gozitans.

The story that surfaced most in interviews with consultants was that of "the sunken village", an event that took place in Kercem, Gozo. As the story goes, people were acting "immoral" or "wicked" at the site of a church, which caused an earthquake to engulf the entire village. This was referred to by one consultant as "the only earthquake in Gozo". Another consultant shared: "Earthquakes in Gozo are quite uncommon and they can be predicted". When asked to elaborate, they said that a priest from Zebbug was able to foretell events such as this. Both earthquake related narratives were noted in literature contained in the archives of Gozo (Attard, 
46-47). The literature refers to such stories as "aetiological legends" or "legends which tell a story to explain some natural phenomenon" (Attard, 50). Another example of this is a Maltese recounting of a quarrel between the land and sea which ultimately serves to explain why the sea is occasionally "rough" or "angry" (Attard, 50).

A form of TEK, aetiological oral histories and lore related to climate and disaster can be found in non-scientific knowledge paradigms globally (Thi Bich Hop et al. 2017). One consultant shared that Malta now has a seismic monitoring group that helps predict both earth and sea quakes but that "they're all science-based" and that "stories aren't something they really think about". Through these excerpts this consultant acknowledged that different ways of knowing exist while expressing gratitude that Malta now has access to these technologies, showing no animosity towards the group or scientific knowledge. This brings up the notable point that local and scientific knowledge do not need to be mutually exclusive but, as explained by Mercer et al. can coexist and operate valuably alongside one another (Mercer et al. 2010, 214-234). However, given the power and prioritization science is granted as the dominant knowledge system, it is well documented that this process requires collaboration and the "recognition by associated stakeholders that Indigenous [in this case local] knowledge is a crucial component of a potential strategy in reducing vulnerability to environmental hazards" (Mercer et al. 2010, 234). Only through this acknowledgment, mutual respect, and communication between all parties, will such a partnership be conducive to effective collaboration and risk reduction (Cronon et al. 2004).

Oral histories and beliefs relating to the sea make up a large portion of Gozitan lore. Two terms that appeared in interviews were "tromba" and "dragunara", words that were not contextualized or defined by consultants but were discussed in relation to storms and incidents that disrupt fishing and salt production. In one instance I asked for clarification and was told: 
"Dragunara - yes the sea, Dragunara is of Malta". When asked about Tromba, I was told by one consultant that it is a "dangerous sea wind" and by another that "fisherman have always feared her." I consulted archival records to better understand the significance of these words and found Dragunara described as the place-name of a cavernous water-reservoir where 'noises' are heard. Though some believe the origin of the noise to be eels that breed within it, others believe the sound to come from a sea monster, "La Dragunara", a tempest personified as a woman or witch (Pullicino 1992, 163). In one story, when asked where she (Dragunara) is going, she replies that she is "out to uproot trees and to destroy all sorts of animals" (Pullicino 1992, 163). This particular text, in reference to Dragunara, explains that "formulas" or "exorcisms" can be practiced in order to "counteract the effects of the tromba". In another excerpt, the author defines tromba (t-tromba) as: phenomena in which a whirling cloud forms a funnel-shaped pendant, which descends towards the sea and draws up a corresponding volume of whirling water, the whole forming a pillar and uniting sea and cloud (Cassar-Pullicino 1992, 162).

From what I can gather, tromba is a sea-storm like phenomena that is caused by La Dragunara, but which people can prevent or mitigate through prayers, verse recitation, exorcism, and other interaction with 'her'. The modern acceptance of belief in such a being is not accounted for in this research but it remains significant in that it surfaced in discussion as a way to reference and talk about disaster and climatic occurrences. Wenger and Weller, disaster studies scholars, share that within subcultures or localities, beliefs about the nature of a particular climatic event as well as "legends of the exploits of others in past disasters and myths about various aspects of the disaster experience are likely to develop" (Wenger and Weller 1973, 1). This observation speaks to the functional quality of oral histories and lore in creating a sense of urgency and 'blueprints' for behavior prior to, during, and following a disaster scenario (Wenger and Weller 1973, 1). This was evidenced in consultant interviews in that past encounters with 'La Dragunara' and subsequently, 
'tromba' inform future action relating to the preparation for, mitigation of, or response to such encounters. One consultant referred to 'tromba' as the reason they were pulling all of their patio furniture into their building one evening. Upon asking for clarification, they shared:

They'll [the patio furniture] be taken away, washed away in the night, oh definitely. It would take you too! [laughter] You can't leave things out on nights like tonight, she's all stirred up and it's bad luck to think you'll have luck-I think so anyway.

The following morning, walking down to the bay, I observed them scraping jellyfish off the side of their building and tossing them into a bucket to be thrown back into the sea and moving their patio furniture back outside. They had successfully evaded, at the least an inconvenience and at the most a potentially dangerous scenario - one that was mitigated by their adherence to the warnings coded in place-based experiences and oral histories specific to the island.

Another occurrence that is related to the "perils of the sea" and is much more widely commented on and observable in Gozo, is the aforementioned "Evil Eye" (Pullicino, 161). Some records say the "Evil Eye" originated through the story of a man who would inflict bad luck on anything he set eyes upon, once admiring a stone and causing it to split in two (Attard, pg. 50). Others relate this to fear that people can curse others with a mere glance to cause hardship at sea. No matter its origin, the placing of "protective eyes" on boats are a longstanding Gozitan custom. Such eyes can be seen on some fishing boats along the island's shores and are noted as either protection from these ancient curses or seen as the ever-guiding "eye of god" (Pullicino, 161). In this instance, whether or not either of these stories are believed separately or in conjunction, the "protective eyes" are a tradition that honors the intent to avoid "maleficent influence" that plagues seaman and maritime people (Pullicino, 161). When asked about the significance of these decals, a myriad of responses surfaces ranging from playful to serious: "I don't know why we still have them to be honest with you but, I'd never take it off"; "I think it's meant to freak tourists out- 
well not originally_it's all mystical to them, you know? Like ooo an evil eye! [laughter] But I'm not a seaman so don't ask me.”; “for me, well, I don't know what I believe it's protecting me from but as a fisherman you gotta be careful, see [gestures to the sea], and I think it helps me remember that, think about it when I set out." This speaks to the adaptive quality of local knowledge. It is common for traditional and localized knowledge to be perceived as static when in reality it is processual and therefore can even more saliently understand and lend insight to the impacts of unfolding events such as climate change (Lejano et al. 2013,4). These experiences of consultants make clear the contemporary relevance of place-based knowledge, even when held in the form of stories and personal histories.

\subsection{Stability in Tradition, Uncertainty in Modernity}

There exists a tension between traditional Gozitan conceptions of 'stability' and the encroachment of modern practices intended to promote 'safety.' Modernity is often viewed as a particularly "occidental process" which, in order to be embraced, requires the abandonment of tradition (Galland and Lamel 2008, 153). Though tradition and modernity are not binaries, and can both exist as contemporary and even complementary systems, modernity is often met with hesitancy as it is characteristically and historically undergirded by western rationality that tends to erase and invalidate traditional systems (Lejano et al. 2013, 1-3). Lejano et al. describes this distinction quite explicitly: "Modern knowledge is an expert driven discourse, in which a knowledge gap exists between speaker and listener" (Lejano et al. 2013, 2). Scholars have acknowledged that the push of modernity, especially when driven by technocracy, can create tension and come into conflict with existing social formations (Avila, 18-19). In this way, risk reduction and disaster mitigation strategies were commonly seen by consultants as opposing tradition and imposing disruptive infrastructural measures. 
Uncertainty is an inevitable feature of climate change and plays a prominent role in shaping pre- and post- disaster circumstances (Afifi et al. 2012, 330). Many consultants expressed a conflict between the current stability they feel in their environment and the uncertainty that risk presents as well as the threat it may pose to that very stability. One consultant acknowledged that they are somewhat resistant to change, despite the possibility that rebuilding infrastructure could reduce hazards. They argue that "even if something collapses every so often" they would rather take that chance than rebuild everything; "I was born here, I am happy like this." To Gozitan consultants, both action and inaction held measurable risk. One way consultants expressed this conflict was through disdain for encroaching infrastructural changes that, while built according to current safety policies, threaten their traditional environment. In one interview, a consultant gestured to Xlendi Bay and said: "See these tall buildings here? They make them nine stories now- nine stories! It's becoming like Malta now, or maybe the U.K.- Ugly." It was common for consultants to make distinctions between themselves and the Maltese, expressing concern that Gozo was becoming more like the mainland. Another consultant shared that they felt traditional Gozitan homes were rather resilient to the climate because they are typically only one or two stories tall and are made of stone, unlike newer buildings that are built high, made of concrete, and are more likely to suffer damage in a disaster, even if they are built to code. When asked about their perspective on newer real estate on the island they shared:

Of course, no-one likes it, right? I mean, I don't. But, these buildings, they aren't for me, they're for tourists, for visitors. There is no planning ahead, if people want to build, they build. They don't consider the consequences. There are building codes, but someone makes a building just slightly higher than the code, and the next person makes the next one slightly higher than that. We can't win, ya know? All the money is in tourism, we have to compromise. The time of year when the seas are angry, the skies are angry, they're all gone, so to tourists it is a pretty safe place to be, yeah. 
This anecdote demonstrates a tension between tourism and tradition that was expressed in several interviews. Additionally, it sheds light on decisions made in the short term for economic stability and stimulation that create hazards in the long term by ignoring infrastructural concerns. Therefore, factors including "local culture, economics, politics, ecology, and infrastructure" all converge to create the conditions of the pre- and post- disaster milieu (Koons 2020, 91). In this way, the political ecology of a community plays a major role in shaping risk.

Place attachment is a well-documented phenomenon that is considered "central to the human experience" (Scannell 2016, 158). Attachment to place in Gozo, goes deeper than simply housing style and safety. Gozo has a notable house naming tradition, where homes are given a title that relates to the family that lives there. The name could be anything from a descriptor of the family's heritage or pastimes to a nickname that suits them. Villages are named after patron saints and have celebrations hosted by each village to honor them. Additionally, as previously mentioned, much of the island's natural features and human-made structures alike, are imbued with lore (Attard, 42-45). Scholars suggest that place attachment can "inhibit pre-disaster resilience, such as when the adaptive changes that are required to bolster community resilience threaten existing place meanings or place identity" (Scannell 2016, 162). In this way, especially given the heightened significance attributed to place in Gozo, it is unsurprising that consultants expressed resistance to changes in their built environment.

In relation to gradual loss and environmental degradation on the island, as opposed to infrastructural changes, I observed several instances where these "natural processes" were seen as "part of life", "to be expected", and something that simply must be adapted to. This cultural disposition towards such shifts is affirmed in an ethnographic account that speaks to notions of fate in Gozo and the tendency for Gozitans to not "try to feign control over that which they 
ultimately have no authority" (Heinze 2016, 651). Additionally, the aforementioned tendency for coastal communities to see the 'unfolding' nature of climatic events to the effect of having a reduced sense of urgency, is once again apparent (Fiske and Marino 2020). The recent collapse of the Azure Window, a beloved feature of the island and a prominent tourist attraction, was described by one consultant who lived near it as "not the disaster it was made out to be" and by another as simply "the way it goes". In contrast to this laissez-faire perspective, however, another consultant shares in frustration, "right after things like this happen, there's a big fuss over securing places, putting money into the environment, even picking up trash, then boom, nobody cares, nothing really happens". Both of these perspectives reveal a connection to place but represent two different courses of action: one that retains tradition for as long as possible even at the risk of hazards emerging, and one that takes swift action to mitigate hazards, embracing modernity, even if it means losing some beloved aspects of one's environment. These actions mirror the concept of equilibrium and non-equilibrium in relation to one's environment as introduced by Scheffer and Carpenter (2003). Populations and their respective ecosystems are constantly in flux but settle into a sort of equilibrium state in which shifts in the ecosystem do not extend far past, and generally return to this "normal" state. However, there are occasionally occurrences in ecosystems that cause more dramatic shifts, whether sudden or slowly built up to a point of extremity. This can cause a given ecological community to enter a non-equilibrium state, pushing it over its threshold of subtle variations and into a new equilibrium state that characterizes stability for that ecosystem, as illustrated in the resilience literature (Scheffer and Carpenter 2003, 650). This is relevant because how one perceives their environment and its ability to retain stability, can impact one's sense of connection to the land and willingness to accept or implement change. Of course, the two perspectives represented here are not unequivocal and as one consultant states: "it is one thing to 
say you're ready for change, and another thing to actually change how you live". These themes emerged frequently in consultant interviews and speak to the convolution and complexity of localized preventative action. Individuals often experience distress when their environment has undergone significant changes or no longer feels like 'home' (Glenn et al. 2007). As such, consultants expressed uncertainty associated with modernity and desire to cling to tradition. It is worth considering how efforts to incorporate local knowledge and values in risk reduction rather than imposing purely technocratic solutions could be more palatable and effective in engaging diverse communities in preventative action. These consultant perspectives speak to the unique place Gozitans find themselves located in the fight to preserve place-based knowledge while being bombarded by globalized initiatives that serve a different narrative of risk and resilience than their own.

\subsection{Climate Contested}

A major confounding factor in how Gozitans perceive and account for risk is the layer of institutional, national, and global narrative in which it is implicated. Themes that habitually emerged in interviews were national incorporation into the EU, dissimilarity between values and concerns of Gozo versus Malta, and the existence of the Emergency Response and Rescue Corps (ERRC).

Distinguishing between Maltese and Gozitan climate, touristic, and political discourses is important as local versus national perspectives seem to differ widely, yet many articles and research studies that exist, talk about them as homogeneous, making claims for Malta at large that do not necessarily represent dominant Gozitan viewpoints (Dodds and Kelman 2008; Satariano and Ritienne 2019; Jones 2017; Galdies 2016). It became immediately apparent in interviews that this distinction was important to consultants and that most interviewees prioritized local rather 
than national identity. Conversely, many consultants cited instances of Maltese national climate initiatives as not being implemented as completely in Gozo. One example of this is the National Disaster Response Team, a facet of the Malta Red Cross that is located in Malta and, according to consultants', views providing support in Goztitan communities as "kind of an afterthought." Other examples of this ranged from conservation efforts receiving less funding in Gozo, to reduced preventative planning.

Another factor that seemed to impact Gozitan perceptions of risk is their incorporation into the EU in 2004. Despite any negative sentiments towards this political shift, consultants expressed a resounding sense of confidence in their ability to be resilient to climatic events, given the E.U. 's now-obligatory support for them. One consultant's response well-articulated this perspective: 'Malta has been a republic since 72'. 1997, totally free. But if there is a disaster, we have Europe. Europe has to help us, it's like a club." It is worth noting that this perspective relies on the hope of disaster response rather than the mitigation of hazards that lead to these events in the first place and reintroduces concerns of how resilience agendas at the global (in this case EU) level undoubtedly differ from local conceptions of resilience (Klein 2007). Despite recent attention to the gaps in project implementation theorized at the global level and applied at the local level, most initiatives (particularly regarding disaster risk reduction, resettlement, preventative action, etc.) are "the product of an ideology that privileges infrastructural development" relegating rights and desires of local communities to a lower level of prioritization (Oliver-Smith 2020, 200). This is significant as many consultants felt that their association with a larger entity such as the EU affords them the security to avoid taking steps towards hazard mitigation. In reality, this approach enables stability in the short term while jeopardizing both tradition and safety in the long-term. 
In searching for any semblance of hazard reduction organizations or structures on the island, I initially encountered several dead ends. After following several leads to supposed disaster mitigation non-profits, governmental organizations, and even businesses, I was met with spaces that were either no-longer operating or did not actually serve the purpose I had initially understood them to. Only one organization was still traceable and actively providing public services relating to hazard reduction, the ERRC. The ERRC was first referenced in a conversation with a consultant who laughed and said: "If anything happens, the Emergency Response and Rescue Corps [ERRC] is always the first to show up". When asked to elaborate on the role of this group, another consultant shares:

Mostly they're volunteers, some government workers, mostly kids. They help out with first aid, fires, and sea and construction accidents, they mostly take care of the jellyfish [laughter], they're like our Baywatch.

The general attitude toward the ERRC by consultants felt indifferent and somewhat removed. In conducting background research on the organization and then receiving a tour of the headquarters in Gozo, I learned that the majority of volunteers are students and young people. In an interview with an ERRC volunteer, I was told that:

No disaster protocol exists yet in Gozo but there is one in the works. It is kinda on the backburner right now, especially in summer months. It always gets started and then stopped and, in the meantime, we just hope for the best.

From what I understand, the individuals volunteering at the ERRC are able to take on small scale projects of their own in local communities in which they are working. Though in theory this leads to a diversity of concerns being met, consultants shared that this often leads to projects going unfinished or dropped when a volunteer is relocated. This is a classic example of gaps between theory and practice in risk reduction, often resulting in a chasm between what is needed and the resources available to meet those needs (Thomas 2020, 115). The volunteer consultant I spoke 
with expressed real concern relating to lack of preparedness on the island paired with increasing climatic risk but felt powerless within the larger structure and the resources they were provided to make any substantial changes. As evident in this case, despite the intents of individual practitioners and volunteers, prevention and response efforts are deeply dependent on "power, political relations, and resources among governments, institutions, and individuals" (Thomas 2020, 115). It is worth noting that at the time I conducted my research, I was not yet aware of the radical community organizing groups that I have since been informed are making substantial contributions towards community resilience. This is an exciting development that speaks to the possible shift towards Gozitans framing resilience in their own terms.

In combination, these themes speak to the complex theatre of interaction that Gozitans exist in that informs climate narratives, perceptions of risk and preventive action on the island as well as the role that technocratic knowledge and those institutions produced by technocracy play in shaping it. The first theme revealed that linguistic disposition plays a role in how climate is discussed and related to in Gozo, creating a dissonance between local climate discourses and larger stakeholder entities. The second theme speaks to the function of oral histories and lore as a prominent way in which climatic events are accounted for in Gozo as well as the insight that they can lend to risk reduction efforts due to their adaptive quality. The third theme illustrates the tension that exists between tradition and modernity in Gozo, particularly in the context of modernist approaches to risk reduction which have failed to incorporate and account for place attachment and relationship to tradition, reducing the salience of such strategies. The fourth and final theme highlighted in this research is the division between local and national narratives of climate risk and safety, directly correlating to inconsistent risk reduction efforts at various institutional levels, often insufficiently accounting for local resilience objectives. 


\section{Conclusion}

In this paper I posit that Gozitan place-based knowledge and perceptions of risk are complex, insightful, and relevant to environmental hazard reduction and disaster risk mitigation. I first offered an outline of the existing theory relevant to this work; in particular I introduced political ecology as an effective theoretical framework and lens through which to explore this topic. Additionally, I highlighted the philosophical and ideological fallacy of the human-nature dichotomy, in order to demonstrate that such fallacious reasoning will obfuscate one's understanding of Gozitan relationships to the environment, and that it is only through the abandoning of such logics that a deeper understanding of place-based knowledge may be achieved. I then offered a context-specific definition of the term's 'resilience' and 'Traditional Ecological Knowledge' as they relate to Gozitan climate and disaster dispositions. Having established this theoretical and philosophical basis, I provided a brief geographic, historic, and cultural background in order to contextualize the research I conducted and to help frame the significance of this topic. Thereafter, I presented my multi-method ethnographic research collection design which included a primary phase of archival and observational research and a secondary phase of informal and semi-structured interviewing. My initial phase of research informed the subsequent phase where I thematically analyzed consultant interviews in order to deduce the most pervasive themes. Through discussion of these themes-language shaping climate discourse, place-based oral histories and lore as impacting risk perception, tension between tradition and modernity in risk reduction, and conflicting climate narratives characterizing the nature of preventative action-I put forth the argument that Gozitan relationships to conceptions of climatic safety and risk are 
place-based and rooted in linguistic, folkloric, traditional and political connections to the island which inform the way climate risk is discussed, perceived, and acted upon at the local level.

This research provides insight into why it is necessary for disaster risk reduction discourses and initiatives to take into account local perspectives and place-based knowledge. It reinforces the claim that traditional knowledge "has a place alongside that of scientific knowledge" (Lejano et al. 2013, 14). Despite the WRI labeling Malta "the second safest country in the world", this ranking cannot predict catastrophe, especially as the effects of climate change increase and make potential harm difficult to anticipate and account for. Both the national and global narrative of Malta is one of safety and security, but this research shows that individual Gozitan perspectives prove to be much more complex. This research also speaks to the heterogeneity of relationships to the climate and thus the necessity of diversifying the types of knowledge garnered in an effort to anticipate and mitigate risk. Without accounting for these variations across cultural contexts, those seeking to mitigate disaster and the increasing effects of climate change may find themselves talking past and even harming those very communities they seek to serve (Kier 2014, Perouse de Montclos 2014).

I believe that the precarity of Gozo in this anthropogenic era of climate change warrants continued attention. Moving forward, further research into the emerging radical community-based climate initiatives and how they are reclaiming their agency and approaches to resilience through community organizing and mutual aid, is necessary. These groups rooted in community are deserving of consideration in this discourse and have much knowledge to share. Scholars, practitioners, and community activists alike have called on the international community to acknowledge the value of traditional and place-based knowledge systems (Mercer et al. 2010, 233). Though the acceptance of non-technocratic knowledge systems is becoming increasingly 
widespread, there is still much need for stakeholder recognition of the validity and value of localized knowledge and its cruciality in reducing environmental hazards (Mercer et al. 2010, 234). Ideally, future research and intervention would entail further collaboration with communities and apply a sense of urgency to the task of prioritizing hazard reduction and resilience at the local level. It is crucial that information sharing takes place between disciplines and across local and global scales. We know that knowledge can help reduce vulnerability and exposure to risk and it is the responsibility of all disciplines adjacent to this effort to share knowledge prior to calamity, rather than in response to it. 


\section{References}

Adger, W. Neil. 1997. "Sustainability and social resilience in coastal resource use." Center for Social and Economic Research on the Global Environment (CSERGE), 1-39. http://citeseerx.ist.psu.edu/viewdoc/download?doi=10.1.1.663.1547\&rep=rep1\&type=pdf

Afifi, Tamara D, Afifi, Walid A, Merrill, Anne F, and Nimah, Najib. 2016. "'Fractured communities': Uncertainty, stress, and (a lack of) communal coping in Palestinian refugee camps." Journal of Applied Communication Research, 44(4), 343-361.

Aikenhead, Glen S. 2008. "Objectivity: The Opiate of the Academic"? Cultural Studies of Science Education, 3:581-585.

Albrecht, Glenn et al. 2007." 'Solastalgia': The Distress Caused by Environmental Change." Australaisian Psychiatry, 15(1): S95-S98.

Alcadipani, Rafael and Damian Hodgson. 2009. "By any means necessary? Ethnographic Access, Ethics, and the Critical Researcher.” Tamara Journal, 7(7.4): 1532-5555.

Allen, Irma. 2014. “'Water, water everywhere but not a drop to drink': The Lived Experience of Scarce Water and its Social Meaning in Gozo, Malta." Omertaa Journal of Applied Anthropology, 623-627.

Allen, Robert L. 2005. "Reassessing the Internal (NEO) Colonialism Theory". The Black Scholar: Journal of Black Studies and Research, 35(1):2-11.

ARGOS Multilingual. 2016. "How Language Shapes Our Perception of the World." July 12, 2016.

https://www.argosmultilingual.com/blog/how-language-shapes-our-perception

Attard, Anton F. 2010. "Narrative Lore of Malta and Gozo." in Folklore in the Maltese Islands, edited by Eucar Mizzi, 47-52.

Avila, Eric. 2014. The Folklore of The Freeway: Race and Revolt in the Modernist City. University of Minnesota Press.

Barrios, Roberto E. 2020. "Unwieldy Disasters: Engaging the Multiple Gaps and Connections 
That Make Catastrophes." In Disaster Upon Disaster: Exploring the Gap Between Knowledge, Policy and Practice, edited by Hoffman Susanna M. and Barrios Roberto E., 23-40. New York; Oxford: Berghahn Books.

Bergman, Ann. 2020. "Future Matter Matters: Disasters as a (Potential) Vehicle for Social Change-It's About Time." In Disaster Upon Disaster: Exploring the Gap Between Knowledge, Policy and Practice, edited by Hoffman Susanna M. and Barrios Roberto E., 313-32. New York; Oxford: Berghahn Books.

Berkes, Fikret. 2008. "Context of Traditional Ecological Knowledge" in Sacred Ecology: Traditional Ecological Knowledge and Resource Management, Philadelphia: Taylor and Francis, 3-15.

Berkes, Fikret and Nancy J. Turner. 2006. "Knowledge, Learning, and the Evolution of Conservation Practice for Socio-Ecological System Resilience". Human Ecology, 34(4): $479-494$.

Bernard, H. Russell. 2017. "Research Methods in Anthropology: Qualitative and Quantitative Approaches." Rowman and Littlefield.

Briguglio, Michael. 2015. “Ten years of Malta's EU membership - the impact on Maltese environmental NGOs: Reflections of a Decade of EU Membership: Expectations, Achievements, Disappointments and the Future Occasional Papers". University of Malta, Institute for European Studies 7: 1-22.

Brullo, Salvatore, Cristian Brullo, Salvatore Cambria, Gianpietro Giusso del Galdo. 2020. "Physiography. In: The Vegetation of the Maltese Islands." Geobotany Studies (Basics, Methods and Case Studies).

Cassar-Pullicino, J. 1992. "Some Maltese Traditions About the Sea." in Studies in Maltese Folklore, 155-164. Malta University Press.

Cilia, Johnathan. 2019. “'Tsunamigenic’: Malta Massively At Risk Of Seismic Disasters Without Proper 24/7 Monitoring System, Apparently". Lovin Malta. May 14, 2019. https://lovinmalta.com/lifestyle/environment/tsunamigenic-malta-massively-at-risk-ofseismic-disasters-without-proper-24-7-monitoring-system-apparently/

Conrad, Elisabeth, Ioan Fazey, Michael Christi, and Charles Galdies. 2019. "Choosing landscapes for protection: Comparing expert and public views in Gozo, Malta." Landscape and Urban Planning 191: 103621. 
Cronon, Shane J. et al. 2004. "Participatory methods of incorporating scientific with traditional knowledge for volcanic hazard measurement on Ambae island, Vanuatu". Bulletin of Volcanology, 66(7): 652-658.

Dadusc, Deanna and Pierpaolo Mudu. 2020. "Care without Control: The Humanitarian Industrial Complex and the Criminalisation of Solidarity". Geopolitics.

Dodds, Rachel and Ilan Kelman. 2008. "How Climate Change is Considered in Sustainable Tourism Policies: A Case of The Mediterranean Islands of Malta and Mallorca". Tourism Review International 12(1): 57-70.

Dupuy, Alex. 2011. "One year after the Earthquake, Foreign Help is Actually Hurting Haiti." The Washington Post, January 7, 2011. https://www.washingtonpost.com/wpdyn/content/article/2011/01/07/AR2011010703043.html

Ecological Threat Register. 2020. "Ecological threat register 2020: Understanding ecological threats, resilience and peace". Institute For Economics and Peace. September 9, 2020. https://reliefweb.int/report/world/ecological-threat-register-2020-understandingecological-threats-resilience-and peace\#: :text=This\%20is\%20the\%20inaugural\%20edition,and $\% 20$ provides\%20projectio ns $\% 20$ to $\% 202050$.

Fiske, Shirley J., and Elizabeth Marino. 2020. "Slow-Onset Disaster: Climate Change and the Gaps between Knowledge, Policy, and Practice." In Disaster Upon Disaster: Exploring the Gap Between Knowledge, Policy and Practice, edited by Hoffman Susanna M. and Barrios Roberto E., 139-71. New York; Oxford: Berghahn Books.

Forgie, Keir. 2014. "US Imperialism and Disaster Capitalism in Haiti” In Good Intentions: Norms and Practices of Imperial Humanitarianism, edited by Maximilian C. Forte. Montreal, QC: Alert Press.

Galdies, Charles, and Johann Galdies. 2016. "From climate perception to action: strategic adaptation for small island farming communities: a focus on Malta." International Center for Advanced Mediterranean Agronomic Studies: CIHEAM Watch Letter 37: 6.

Galland, Olivier and Yannick Lamel. 2008. Tradition vs. Modernity: The Continuing Dichotomy of Values in European Society." R. franç. sociol. 49: 153-186.

Heinze, Jerika. 2016. "When God Pulls Your Card: Fate and Risk Taking Behavior in Malta." Omertaa Journal of Applied Anthropology, 648-654. 
Johnson-Laird, Philip N. and George A. Miller. 2013. "4. Labels, Words, and Concepts" In Language and Perception, 212-321. Cambridge and London: Harvard University Press.

Jones, A. 2017. “Case Study Malta: Climate Change and Tourism: Risks, Hazards, and Resilience- an Island Perspectives" In Global Climate Change and Coastal Tourism: Recognizing Problems, Managing Solutions and Future Expectations, edited by Andrew L. Jones and Michael Phillips, 138-146. CABI.

Klein, Naomi. 2007. The Shock Doctrine: The Rise of Disaster Capitalism. London: Penguin Press.

Koons, Adam. 2020. "Humanitarian Response: Ideals Meet Reality." In Disaster Upon Disaster: Exploring the Gap Between Knowledge, Policy and Practice, edited by Hoffman Susanna M. and Barrios Roberto E., 88-110. New York; Oxford: Berghahn Books.

Lejano, Raul P., Joana Tavares, and Fikret Berkes. 2013. "Climate Narratives: What is Modern about Traditional Ecological Knowledge"? School of Social Ecology, 1-16.

Leone Ganado, Philip. 2018. "Malta needs to prepare for climate change, experts say." Times of Malta, October 15, 2018. https://timesofmalta.com/articles/view/malta-needs-to-prepare-for-climate-changeexperts-say. 691503

Malta Independent. 2019. "World Risk Report ranks Malta as the world's second-safest country for natural disasters again.” Malta Independent, September 13, 2019. https://www.independent.com.mt/articles/2019-09-13/local-news/World-Risk-Reportranks-Malta-as-the-world-s-second-safest-country-for-natural-disasters-again$6736213465 \backslash$

Malta Tourism Authority. 2021. “Timeline.” Visit Malta, February 11, 2021. https://www.visitmalta.com/en/timeline

Martin, Callum. 2015. "Do Colonial Attitudes Influence the Media's Response to the Humanitarian Aid Crisis"? E-International Relations, July 82015. https://www.e-ir.info/2015/07/08/do-colonial-attitudes-influence-the-medias-response-to humanitarian-crises/

Mercer, Jessica, Ilan Kelman, Lorin Taranis and Sandie Suchet-Pearson. 2010. "Framework for 
Integrating Indigenous and Scientific Knowledge for Disaster Risk Reduction.” Disasters, 34(1): 214-239.

Mifsud, Mark and Silvana Sultana. 2019. "Knowledge, Values and Attitudes Towards Marine Protected Areas in Gozo (Malta)" in Social Responsibility and Sustainability: How Businesses and Organizations Can Operate in a Sustainable and Socially Responsible Way, edited by Walter Leal Filho, 75-91. Springer.

Okely, Judith. 2012. “Confronting Positionality.” Teaching Anthropology, 2(1):36-43.

Oliver-Smith, Anthony. 2009. "Anthropology and the Political Economy of Disasters" In The Political Economy of Hazards and Disasters, edited by E.C. Jones and A.D. Murphy, 1128. New York: Altamira Press.

Oliver-Smith, Anthony. 2020 "Resettlement for Disaster Risk Reduction: Global Knowledge, Local Application." In Disaster Upon Disaster: Exploring the Gap Between Knowledge, Policy and Practice, edited by Hoffman Susanna M. and Barrios Roberto E., 198-217. New York; Oxford: Berghahn Books.

Pérouse de Montclos, Marc-Antoine. 2014. "The (de)Militarization of Humanitarian Aid: A Historical Perspective.” Humanities 3: 232-243.

Portelli, Jonathan. 2010. “Assessing vulnerability to coastal hazards case study: Gozo”. PhD Diss., James Madison University. 1-150.

Purdy, Jedidiah. 2015. “After Nature: A Politics for the Anthropocene.” Cambridge, Massachusetts; London, England: Harvard University Press.

Purdy, Jedidiah. 2016. “The New Nature”. Boston Review, January 11, 2016 http://bostonreview.net/forum/jedediah-purdy-new-nature

Robbins, Paul. 2012. "What is Political Ecology?” In Political Ecology: A Critical Introduction, edited by Paul Robbins, 1-48. Chicago: Wiley Press.

Robbins, Paul and Sarah A. Moore. 2013. "Ecological Anxiety Disorder: Diagnosing the Politics of the Anthropocene." Cultural Geographies 20 (1): 3-19. 
Robertson, Jennifer. 2002. "Reflexivity Redux: A Pithy Polemic on 'Positionality’." Anthropological Quarterly, 75(4): 185-792).

Satariano, Bernadine and Gauci Ritienne. 2019. "Landform Loss and Its Effect on Health and Well-being: The Collapse of the Azure Window (Gozo) and the Resultant Reactions of the Media and the Maltese Community" in Landscapes and Landforms of the Maltese Islands, edited by Ritienne Gauci and John A. Schembri, 289-303. Springer.

Scannell, Leila et al. 2016. “'That was the Last Time I Saw My House': The Importance of Place Attachment among Children and Youth in Disaster Contexts." American Journal of Community Psychology, 58:(1-2) 15-173.

Scheffer, Marten and Stephen R. Carpenter. 2003. "Catastrophic Regime Shifts in Ecosystems: Linking Theory to Observation.” TRENDS in Ecology and Evolution, 18(12):648-656.

Scoones, Ian. 1999. "New Ecology and Social Sciences: What Prospects for a Fruitful Engagement?" Annual Review of Anthropology (28)1: 479-507.

Thi Bich Hop, Hoang, Nguyen Huu Ninh, Le Thi Thu Hien. 2017. "The Role of Traditional Ecological Knowledge in the Disaster Risk Management Strategies of Island Communities in Cat Hai, Vietnam". Climate, Disaster and Development Journal, 2(2): 23-32.

Thomas, Jane Murphy. 2020. "Disaster Theory versus Practice? It Is a Long Rocky Road: A Practitioner's View from the Ground." In Disaster Upon Disaster: Exploring the Gap Between Knowledge, Policy and Practice, edited by Hoffman Susanna M. and Barrios Roberto E., 111-34. New York; Oxford: Berghahn Books.

Torry, William. 1978. "Bureaucracy, Community, and Natural Disasters." Human Organization, 37(3): 302-308.

Wenger, Dennis E. and Weller Jack M. 1973. "Disaster Subcultures: The Cultural Residues of Community Disaster". University of Delaware Disaster Research Center, 1-18.

Zammit, Anne. 2018. "Malta might not be prepared for a natural disaster: What would happen if a massive wave hit Xlendi"? Times of Malta, March 11, 2018. https://timesofmalta.com/articles/view/maltas-natural-hazard-preparednessquestioned.672880 